J. Lake Sci. (湖泊科学), 2006, 18(6):572-578

http:// www. jlakes. org. E-mail: jlakes@ niglas. ac.cn

(c) 2006 by Journal of Lake Sciences

\title{
滇池水体中微囊藻毒素含量变化与环境因子的相关性研究
}

\author{
潘晓洁 ${ }^{1,2}$, 常锋毅 ${ }^{1,2}$, 沈银武 ${ }^{1}$, 刘永定 ${ }^{1 * *}$, 李敦海 ${ }^{1}$ ，李根保 ${ }^{1}$, 肖邦定 ${ }^{1}$ \\ (1: 中国科学院水生生物研究所, 武汉 430072) \\ (2: 中国科学院研究生院, 北京 100039)
}

摘 要: 本文对 2003 年 4-12 月滇池马村湾、海东湾微囊藻毒素和总磷、总氮、溶解氧、透明度、光照强度、叶绿素 $\mathrm{a} 、 \mathrm{pH}$ 值、水温及微囊藻种群优势度进行了分析, 讨论了以上指标在滇池马村湾和海东湾的分布和月变化情况以及与微囊藻毒 素含量之间的关系. 相关性分析表明马村湾、海东湾微囊藻毒素在水体中分布与总氮和氮磷比之间呈现非常显著的负相 关性 $(P<0.01)$; 与透明度、光照强度和微囊藻种群优势度存在显著的正相关性 $(P<0.05)$. 在影响微囊藻毒素的各因素 中, 运用多因素逐步回归分析得知马村湾、海东湾微囊藻毒素浓度主要由水体的总氮、总磷、叶绿素 a 和溶解氧以及透明 度决定 $\left(R^{2}=0.560, P<0.017\right)$.

关键词: 滇池; 微囊藻毒素; 相关分析

\section{The correlation between the variation of microcystin content and environment factors in Di- anchi Lake}

PAN Xiaojie ${ }^{1,2}$, CHANG Fengyi ${ }^{1,2}$, SHEN Yinwu ${ }^{1}$, LIU Yongding ${ }^{1}$, LI Dunhai ${ }^{1}$, LI Genbao ${ }^{1}$ \& XIAO Bangding ${ }^{1}$

(1: Institute of Hydrobiology, Chinese Academy of Science, Wuhan 430072, P. R. China)

(2: Gradute School of Chinese Academy of Science, Beijing 100039,P. R. China)

Abstract: This paper analyzed the distribution and variation of microcystin( MC) and physicochemical factors in Macun and Haidong bay of Dianchi Lake from April to December in 2003. The correlation of some physiochemical factors, including the concentration of total nitrogen, total phosphorous, dissolve oxygen, chlorophyll-a and Seechi depth, light intensity, $\mathrm{pH}$, water temperature and dominance of Microcystis population, with microcystin was evaluated. Correlation analysis showed that the distribution of MC was significantly positive correlated with TN and $\mathrm{N}: \mathrm{P}$ $(P<0.01)$; and affected by Seechi depth, light intensity, dominance of Microcystis $(P<0.05)$. Multiple continuously factors analysis indicated that the distribution of $\mathrm{MC}$ in water of the two bays was mainly affected by total nitrogen, Seechi depth, chlorophyll-a, dissolve oxygen and total phosphorous $\left(R^{2}=0.560, P<0.017\right)$.

Keywords : Dianchi Lake; microcystin; correlation analysis

随着工农业的发展和城市化进程的加快, 工业和生活污水通过各种途径进人水环境中导致水体富营养 化程度加剧, 引起有害蓝藻水华的频繁发生, 这种现象已引起了国内外研究者们的普遍关注 ${ }^{[1]}$. 蓝藻水华 的大量暴发不仅影响水体的自然景观和城市供水, 而且有毒蓝藻产生的微囊藻毒素 (microcystin, MC) 严重 危害着水生态系统的安全. 有毒蓝藻中除危害性很大的微囊藻 (Microcystis) 外, 鱼腥藻 (Anabaena) 及颤藻 (Oscillatoria) 中的很多种也可以产生微囊藻毒素 ${ }^{[2]}$. 世界各地由于有毒蓝藻水华暴发引起牲畜中毒死亡和 对人类健康造成危害的报道己有很多 ${ }^{[3,4]}$. 环境因子在毒素的产生中起着重要的作用,但以往报道的环境 因子对毒素产生的影响多是在实验室条件下进行的, 并且往往只分析单因子对产毒的影响, 而自然条件下 各种影响因子对微囊藻产毒的影响是交互作用的, 因此要了解微囊藻毒素在自然水体中的分布必须将各种

* 973 项目 (2002CB412300) 和中国科学院前沿性创新课题 (220316) 联合资助. 2005 - $09-12$ 收稿; 2005 - 12 - 06 收修改稿.潘晓洁, 女, 1980 年生,博士研究生; E-mail : panxj2008@ 163.com.

** 通讯作者; E-mail: liuyd@ihb. ac. cn. 
影响因素综合起来考虑.

滇池是云贵高原第一大高原湖泊,位于云南省昆明市城区西南面. 近十几年来, 由于人类活动的影响, 滇 池水体富营养化程度加剧, 以微囊藻为优势种的有毒蓝藻水华频繁发生, 湖泊生态系统日益恶化. 本文以滇池 东北部的马村湾和海东湾设立的 $6.1 \mathrm{~km}^{2}$ 非封闭围隔水域为研究对象, 研究了微囊藻毒素在水体中的年时空 分布状况及其影响因素, 以探索微囊藻毒素在自然水体中的发展规律, 为制定有效的防治措施奠定基础.

\section{1 材料与方法}

\section{1 样点分布及采样方法}

在 $6.1 \mathrm{~km}^{2}$ 非封闭围隔水域选取十个样点, 其中马村湾 4 个 $\left(1-4^{\#}\right.$ ), 海东湾 6 个 $\left(5-10^{\#}\right)$ (图 1$)$. 由于 马村湾和海东湾平均水深在 $3 \mathrm{~m}$ 左右, 水体混合性良好, 故采样时每个样点只取表层 $0.5 \mathrm{~m}$ 深度水样一个, 其中 $1 \mathrm{~L}$ 水样以鲁哥氏液固定用于藻细胞计数, $1 \mathrm{~L}$ 水样测定水体理化指标, 同时用 $25^{\#}$ 浮游植物网捞取少 量藻样用于藻细胞定性分析. 采样频率为每月一次,时间为每月月末早上 $9: 00-11: 00$.

\section{2 水体中微囊藻毒素的测定}

量取 $500 \mathrm{ml}$ 水样,用 $0.45 \mu \mathrm{m}$ 醋酸纤维滤膜负 压抽滤, 水样通过已用 $10 \mathrm{ml}$ 蒸馏水和 $10 \mathrm{ml}$ 甲醇活 化过的 Sep - Pak C18 小柱过滤富集藻毒素. 待样品 全部吸附后, 分别用 $50 \mathrm{ml} 20 \%$ 甲醇水溶液作为淋 洗液, $50 \mathrm{ml}$ 甲醇作为洗脱液. 收集甲醇洗脱液, $60^{\circ} \mathrm{C}$ 水浴旋转蒸发仪 (北京 RE - 90) 上浓缩干燥, 剩余 物溶于 $60 \%$ 甲醇, 定容至 $1 \mathrm{ml}$, 取其中部分进行 HPLC 分析 ${ }^{[5]}$.

\section{3 叶绿素 $\mathrm{a}$ 测定方法及微囊藻种群优势度计算}

叶绿素 a 测定方法: 以 Whatman GF/C 玻璃纤 维滤膜抽滤适量水样 (视浮游植物生物量决定,一 般取 $100 \mathrm{ml}$ ), 将带有藻的滤膜研磨后以 $90 \%$ 丙酮 抽提 $12 \mathrm{~h}, 4000 \mathrm{rpm}$ 离心 $15 \mathrm{~min}$,取上清液定容至 10 $\mathrm{ml}$, 以 752 型分光光度计测定 $665 \mathrm{~nm}$ 和 $750 \mathrm{~nm}$ 处吸 Fig. 1 Locations for sampling in Macun bay and Haidong bay 光度, 按照文献描述计算叶绿素含量 ${ }^{[6]}$. 微囊藻种

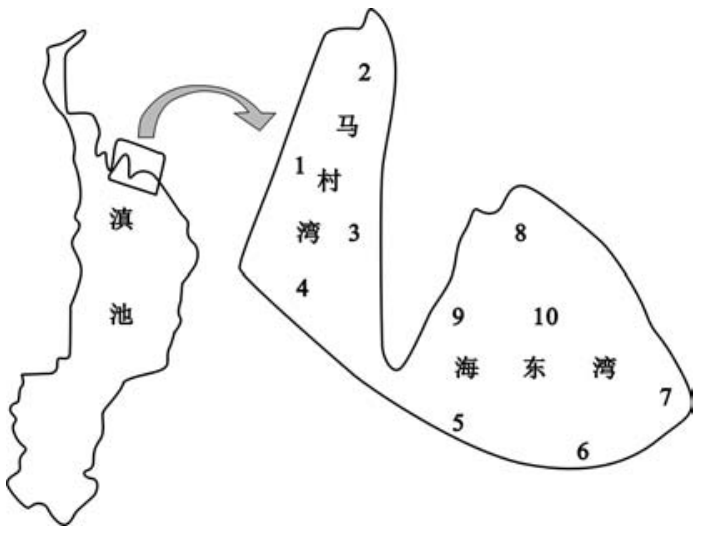
群优势度的计算: 将鲁哥氏液固定水样浓缩后以浮游生物计数框计数, 计算出微囊藻细胞数和藻细胞总数, 以微囊藻细胞个数/藻细胞总数表示微囊藻种群优势度.

\section{4 水化学指标的测定}

采用萨克氏盘及日本 DKK. TOA 公司生产的 HM $-20 \mathrm{P}$ 和 DO - $24 \mathrm{P}$ 水质自动测定仪测定采样点透明度 和 $0.5 \mathrm{~m}$ 水深的 $\mathrm{pH}$ 值、溶解氧、水温. 以 ZDS -20 型 (上海嘉定学联仪器厂) 照度计测量采样时水体表面光 照强度. 总磷采用钼酸铵分光光度法测定, 总氮采用碱性过硫酸钾消解紫外分光光度法测定 ${ }^{[7]}$.

\section{5 分析方法}

将所有数据在 Excel 中建立数据库, 由于微囊藻种群优势度是以百分比表示, 故对其进行反正弦变换, 而其他数据则进行对数变换 (小于 10 的数据加 1 后进行对数转变) 使其符合正态分布, 以 SPSS11.5 进行 Pearson 相关性分析和逐步回归分析.

\section{2 结果}

\section{1 马村湾和海东湾微囊藻毒素分布与变化}

马村湾和海东湾 2003 年 4-12 月 10 个样点微囊藻毒素平均含量为 $0.20 \mu \mathrm{g} / \mathrm{L}$, 其中马村湾 4 个样点 微囊藻毒素平均含量为 $0.18 \mu \mathrm{g} / \mathrm{L}$, 而海东湾 6 个样点微囊藻毒素平均含量为 $0.21 \mu \mathrm{g} / \mathrm{L}$, 略高于马村湾 (表 1), 两处水体中毒素含量均远低于世界卫生组织规定天然水体及饮用水中微囊藻毒素应低于 $1 \mu \mathrm{g} / \mathrm{L}$ 
的标准 ${ }^{[8]}$. 微囊藻毒素含量逐月变化中, 除 4 月份海东湾明显高于马村湾外, 其他月份两个湖湾毒素含量水 平相当,且在 4-12月 9个月份中毒素含量变化趋势相同,均在 4 月和 7 月出现两个较高的峰值 (图 2). 9 个月份中海东湾毒素含量在 $0.05-0.89 \mu \mathrm{g} / \mathrm{L}$ 之间变动, 马村湾毒素含量在 $0.03-0.48 \mu \mathrm{g} / \mathrm{L}$ 之间变动, 表 明两湾在不同月份微囊澡毒素含量变化较大.

表 1 马村湾、海东湾微囊藻毒素及理化数据

Tab. 1 Data of microcystin and physicochemical factors in Macun bay and Haidong bay

\begin{tabular}{cccc}
\hline & 马村湾 & 海东湾 & 平均 \\
\hline 微囊藻毒素 $(\mu \mathrm{g} / \mathrm{L})$ & $0.18 \pm 0.17$ & $0.21 \pm 0.31$ & $0.2 \pm 0.26$ \\
总氮 $(\mathrm{mg} / \mathrm{L})$ & $4.93 \pm 2.97$ & $4.96 \pm 3.28$ & $4.95 \pm 3.14$ \\
总磷 $(\mathrm{mg} / \mathrm{L})$ & $0.31 \pm 0.15$ & $0.26 \pm 0.12$ & $0.28 \pm 0.14$ \\
溶解氧 $(\mathrm{mg} / \mathrm{L})$ & $8.97 \pm 1.92$ & $8.84 \pm 1.14$ & $8.89 \pm 1.49$ \\
$\mathrm{pH}$ & $8.68 \pm 0.26$ & $8.75 \pm 0.22$ & $8.72 \pm 0.24$ \\
透明度 $(\mathrm{cm})$ & $22.3 \pm 8.9$ & $24.2 \pm 8.1$ & $23.5 \pm 8.4$ \\
温度 $\left({ }^{\circ} \mathrm{C}\right)$ & $18.8 \pm 4.1$ & $19.0 \pm 3.9$ & $18.9 \pm 3.9$ \\
叶绿素 $\mathrm{a}(\mathrm{mg} / \mathrm{L})$ & $0.22 \pm 0.14$ & $0.15 \pm 0.07$ & $0.17 \pm 0.11$ \\
光照强度 $(\mathrm{klx})$ & $44.07 \pm 33.18$ & $35.98 \pm 28.07$ & $39.22 \pm 30.3$ \\
微囊藻种群优势度 $(\%)$ & $90.63 \pm 8.13$ & $84.62 \pm 14.24$ & $87.02 \pm 12.5$ \\
\hline
\end{tabular}

\section{2 马村湾、海东湾各项理化因子分布与变化}

马村湾和海东湾理化因子分析结果表明两湾总氮含量相同, 均为 $4.9 \mathrm{mg} / \mathrm{L}$. 总磷含量马村湾较海东湾 高, 因而氮磷比 $(\mathrm{N}: \mathrm{P})$ 海东湾高于马村湾 6 倍. 两湾的溶解氧、 $\mathrm{pH}$ 值、透明度、温度、光照强度无明显差异. 叶绿素 a 含量和微囊藻种群优势度马村湾明显高于海东湾, 这表明马村湾浮游植物生物量高于海东湾, 并 且浮游植物组成单一, 以微囊藻为主 (表 1 ).

各项理化因子逐月变化中除总磷和叶绿素 a 含量在马村湾与海东湾个别月份变化较大外,其他指标在 两湾相差不大,但所有指标在两湾的变化趋势都相同 (图 2). 总氮含量在 4-7 月份变化不大, $8-10$ 月份逐 月递增, 10 月份达最大值 $10.71 \mathrm{mg} / \mathrm{L}$. 总磷含量在 $6 、 8 、 9$ 月份均出现了较高值, 但 $8 、 9$ 月份两湖湾总磷含量 相差较大, 总磷含量的最小值出现在 10 月份, 平均含量为 $0.10 \mathrm{mg} / \mathrm{L}$. 叶绿素 a 含量逐月变化趋势与总磷含 量变化趋势相似,在 6、8、9 月份也出现了较高值,但叶绿素a 含量 10 月份以后则一直降低,至 12 月份两湾 叶绿素浓度均降低至 $0.04 \mathrm{mg} / \mathrm{L}$ 左右. 溶解氧逐月变化呈现周期性波动的特点, 4、5、6 月份溶解氧含量逐月 上升, 7 月份下降, $8 、 9$ 月份又逐月回升至较高值, 10 月份再下降, $11 、 12$ 月份又逐月上升. $\mathrm{pH}$ 值逐月变化不 大均在 $8.30-9.14$ 之间变动, 呈弱碱性. 透明度变化在两个湖湾是相似的, $4-8$ 月份逐月下降, 8 月份最低 为 $11.5 \mathrm{~cm}, 9 、 10$ 月份又缓慢上升, $11 、 12$ 月份由于风季的到来透明度又有所降低. 温度的变化在马村湾和 海东湾是一致, $4-9$ 月份基本维持在 $21^{\circ} \mathrm{C}$ 左右, 10 到 12 月逐渐降低至 $11.1^{\circ} \mathrm{C}$. 光照强度的变化在 $4-10$ 月 份基本呈下降趋势, 随后又小幅度上升,4月份最高为 $98.19 \mathrm{klx}, 10$ 月份最低仅为 $10.54 \mathrm{klx}$. 微囊藻种群优 势度的变化在 4-6 月基本不变, 7 月份最低为 $65.70 \%, 8-12$ 月份则维持在较高水平( $90 \%$ 以上).

\section{3 优势种的鉴定}

通过显微镜定性观察可以确定马村湾和海东湾浮游植物优势种属为微囊藻, 主要包括铜绿微囊藻 $(M i-$ croeystis aeruginosa)、绿色微囊藻 (Microcystis viridis) 和惠氏微囊藻 (Microcystis wesenbergii) 三个种, 其中铜绿 微囊藻占多数. 此外, 4、5 月份经常有水华束丝藻 (Aphanizomenon flos-aquae) 和卷曲鱼腥藻 (Anabaena circinalis) 出现.

\section{4 微囊藻毒素和各因素相关、回归分析}

相关性分析结果表明 (表 2): 马村湾、海东湾水体中微囊藻毒素含量与总氮和氮磷比之间呈现非常显 著的负相关, 与透明度、光照强度和微囊藻种群优势度之间也存在统计意义上的相关性. 此外, 总磷还与微 

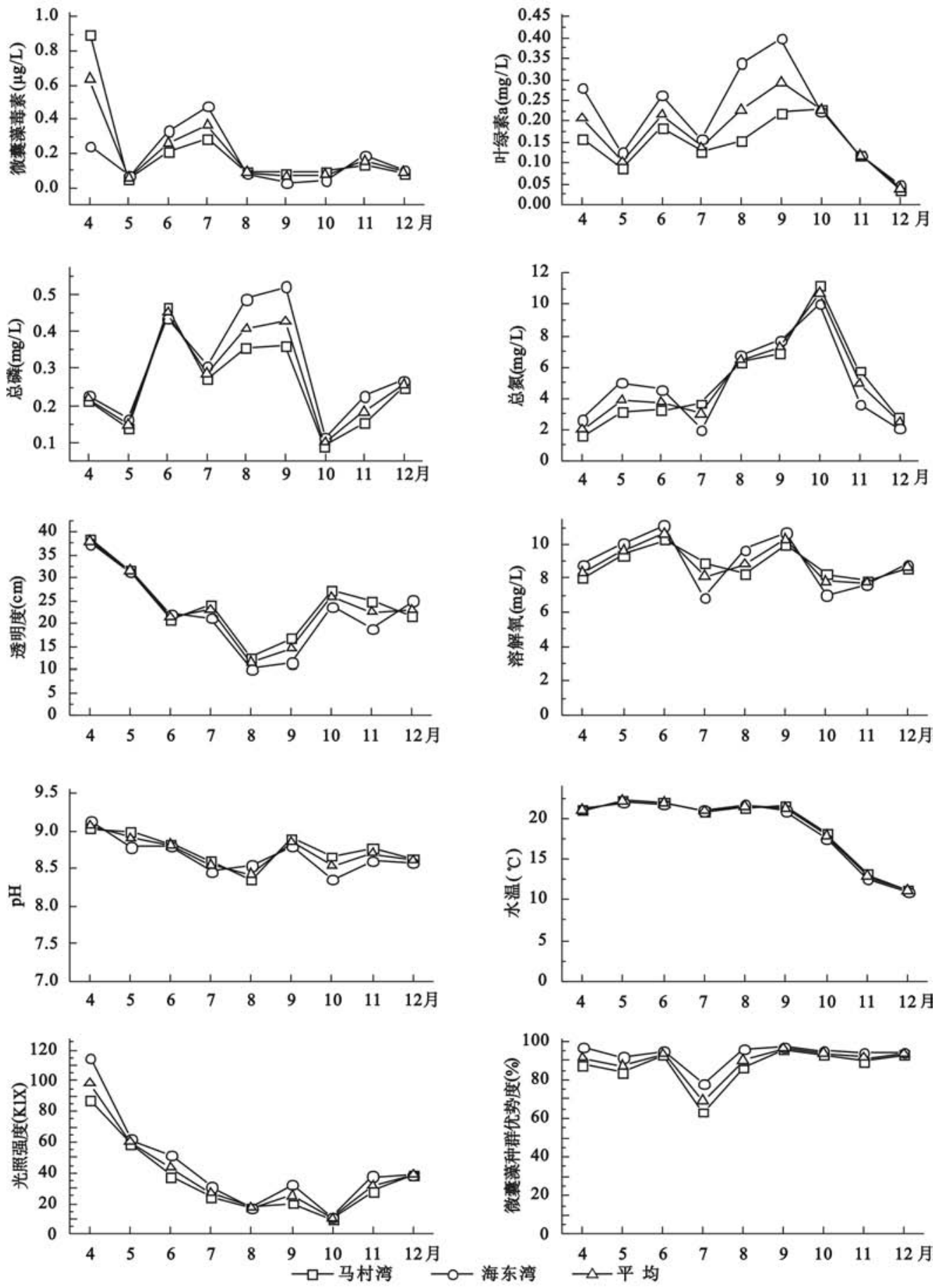

图 22003 年 4-12 月马村湾、海东湾微囊藻毒素及理化因子的变化情况

Fig. 2 Variation of microcystin and physicochemical factors in Macun and Haidong bay during April to December in 2003 
表 2 微囊藻毒素和各理化因子相关性分析 ${ }^{1)}$

Tab. 2 Association analysis between microcystin and physicochemical factors

\begin{tabular}{|c|c|c|c|c|c|c|c|c|c|c|c|c|}
\hline & & 毒素 & 总氮 & 总磷 & 氮磷比 & 溶解氧 & $\mathrm{pH}$ & 唀明度 & 温度 & 叶绿素 & $\begin{array}{l}\text { 光照 } \\
\text { 强度 }\end{array}$ & $\begin{array}{l}\text { 微囊藻种 } \\
\text { 群优势度 }\end{array}$ \\
\hline \multirow[t]{2}{*}{ 毒素 } & $R$ & $1.000-1$ & $-0.490^{* * *}$ & 0.197 & $-0.470^{* * *}$ & $-0.211^{*}$ & 0.142 & $0.223 *$ & 0.132 & 0.064 & $0.290^{* *}$ & $0.229^{*}$ \\
\hline & $P$ & 1.000 & 0.000 & 0.063 & 0.000 & 0.046 & 0.183 & 0.034 & 0.216 & 0.551 & 0.006 & 0.030 \\
\hline \multirow[t]{2}{*}{ 总氮 } & $R$ & $-0.490^{* * *}$ & $* 1.000$ & -0.137 & 0.798 & 0.056 & -0.253 & -0.435 & 0.128 & 0.443 & -0.561 & -0.324 \\
\hline & $P$ & 0.000 & 1.000 & 0.199 & 0.000 & 0.598 & 0.016 & 0.000 & 0.229 & 0.000 & 0.000 & 0.002 \\
\hline \multirow[t]{2}{*}{ 总磷 } & $R$ & 0.093 & -0.039 & 1.000 & -0.578 & 0.363 & -0.085 & -0.671 & 0.313 & 0.414 & 0.020 & 0.302 \\
\hline & $P$ & 0.383 & 0.714 & 1.000 & 0.000 & 0.000 & 0.425 & 0.000 & 0.003 & 0.000 & 0.850 & 0.004 \\
\hline \multirow[t]{2}{*}{ 氮磷比 } & $R$ & $-0.470^{* * *}$ & * 0.798 & -0.706 & 1.000 & -0.108 & -0.163 & 0.064 & -0.057 & 0.146 & -0.474 & -0.119 \\
\hline & $P$ & 0.000 & 0.000 & 0.000 & 1.000 & 0.309 & 0.126 & 0.547 & 0.591 & 0.169 & 0.000 & 0.263 \\
\hline \multirow[t]{2}{*}{ 溶解氧 } & $R$ & $-0.211^{*}$ & 0.056 & 0.363 & -0.108 & 1.000 & 0.329 & -0.059 & 0.467 & 0.157 & 0.234 & 0.067 \\
\hline & $P$ & 0.046 & 0.598 & 0.000 & 0.309 & 1.000 & 0.002 & 0.581 & 0.000 & 0.139 & 0.027 & 0.529 \\
\hline \multirow[t]{2}{*}{$\mathrm{pH}$} & $R$ & 0.142 & -0.253 & -0.030 & -0.163 & 0.329 & 1.000 & 0.426 & 0.237 & 0.150 & 0.530 & 0.102 \\
\hline & $P$ & 0.183 & 0.016 & 0.778 & 0.126 & 0.002 & 1.000 & 0.000 & 0.024 & 0.159 & 0.000 & 0.337 \\
\hline \multirow[t]{2}{*}{ 透明度 } & $R$ & $0.253^{*}$ & -0.394 & -0.671 & 0.055 & -0.059 & 0.433 & 1.000 & -0.040 & -0.269 & 0.386 & -0.495 \\
\hline & $P$ & 0.016 & 0.000 & 0.000 & 0.608 & 0.581 & 0.000 & 1.000 & 0.706 & 0.010 & 0.000 & 0.000 \\
\hline \multirow[t]{2}{*}{ 温度 } & $R$ & 0.132 & 0.128 & 0.245 & -0.057 & 0.467 & 0.237 & -0.070 & 1.000 & 0.645 & 0.105 & 0.206 \\
\hline & $P$ & 0.216 & 0.229 & 0.020 & 0.591 & 0.000 & 0.024 & 0.513 & 1.000 & 0.000 & 0.325 & 0.052 \\
\hline \multirow[t]{2}{*}{ 叶绿素 } & $R$ & 0.064 & 0.443 & 0.281 & 0.146 & 0.157 & 0.150 & -0.313 & 0.645 & 1.000 & -0.133 & -0.197 \\
\hline & $P$ & 0.551 & 0.000 & 0.007 & 0.169 & 0.139 & 0.159 & 0.003 & 0.000 & 1.000 & 0.212 & 0.062 \\
\hline \multirow[t]{2}{*}{ 光照强度 } & $R$ & $0.290^{* *}$ & -0.561 & 0.121 & -0.474 & 0.234 & 0.530 & 0.389 & 0.105 & -0.133 & 1.000 & 0.163 \\
\hline & $P$ & 0.006 & 0.000 & 0.257 & 0.000 & 0.027 & 0.000 & 0.000 & 0.325 & 0.212 & 1.000 & 0.125 \\
\hline 微囊澡种 & $R$ & $0.229 *$ & -0.324 & -0.185 & -0.119 & 0.067 & 0.102 & 0.421 & 0.206 & -0.197 & 0.163 & 1.000 \\
\hline 群优势度 & $P$ & 0.030 & 0.002 & 0.081 & 0.263 & 0.529 & 0.337 & 0.000 & 0.052 & 0.062 & 0.125 & 1.000 \\
\hline
\end{tabular}

$1) *$ 相关 $(P<0.05) ; * *$ 显著相关 $(P<0.01) ; * * *$ 极显著相关 $(P<0.001)$.

表 3 逐步回归分析结果

Tab. 3 The result of stepwise regression analysis

\begin{tabular}{cccc}
\hline 回归变量 & $R^{2}$ & $F$ & $P$ \\
\hline 总氮, 透明度 & 0.435 & 4.89 & 0.030 \\
总氮, 透明度, 叶绿素 & 0.475 & 4.05 & 0.047 \\
总氮, 透明度, 叶绿素, 溶解氧, 总磷 & 0.560 & 5.93 & 0.017 \\
总氮, 透明度, 叶绿素, 溶解氧 & 0.514 & 4.51 & 0.037 \\
总氮, 透明度, 溶解氧, 总磷 & 0.559 & 0.14 & 0.708 \\
透明度, 溶解氧, 总磷 & 0.543 & 2.08 & 0.153 \\
\hline
\end{tabular}

囊藻毒素呈现 Spearman 相关性. 逐步回归分析结果如表 3 , 氮磷比、pH 值、光照强度及微囊藻种群优势度始 终未能进人回归模型. 通过进人回归模型的总氮、透明度、叶绿素、溶解氧、总磷对微囊藻毒素进行预测其 $R^{2}$ 达到 $0.560(P<0.017)$. 按其对微囊藻毒素影响大小依次为透明度 $>$ 溶解氧 $>$ 总磷 $>$ 总氮 $>$ 叶绿素.

\section{3 讨论}

\section{1 滇池马村湾、海东湾理化因子分布与变动成因分析}

滇池地处云贵高原,其独特的热带高原季风气候和水文地质条件在每年 5-10月份带来大量降水的同 
时, 也将滇池流域富含的氮、磷通过地表径流带人了水体中 ${ }^{[9,10]}$. 而马村湾、海东湾沿岸的 7 条人湖河道 (马 村湾 4 条, 海东湾 3 条) 还接纳了大量的工业、农业及生活污水, 造成两湖湾总磷、总氮含量很高且随降水量 和污水排放量而变化的特点, 这为微囊藻水华的暴发提供了营养基础. 影响微囊藻生长的另一个重要因素 $\mathrm{pH}$ 值的变动也与滇池流域广泛分布的碳酸盐岩在适宜的水文地质及构造条件下发生的岩溶作用有关 ${ }^{[11]}$ : 由于碳酸盐岩在水中的分解造成水体 $\mathrm{HCO}_{3}^{-}$和 $\mathrm{OH}^{-}$含量较高, 导致滇池水体偏碱性. 以往的研究表明, 低 $\mathrm{pH}$ (小于 6 ) 值有利于真核藻类生长, 高 $\mathrm{pH}$ (大于 8 ) 值有利于原核藻类生长 ${ }^{[12]}$. 滇池水体的碱性环境非常 有利于原核生物蓝藻的生长, 一旦其生长的其他条件满足即可暴发水华. 此外, 滇池地区较高的光照强度和 合适的温度也非常有利于微囊藻的生长和繁殖. 马村湾、海东湾的溶解氧含量较高, 即使在微囊藻大量生长 的夏、秋季节, 也会由于浮游藻类光合作用对水体有较强的富氧作用而不致使水体中的溶解氧降至太 低 ${ }^{[13]}$. 但是, 由于水华暴发过后浮游藻类大量死亡时会消耗大量的溶解氧, 因此在某些月份也会使水体中 溶解氧降至很低,并且伴随水华的消长呈现周期性变化的特点. 滇池属于浅水湖泊,在冬、春季节风浪较大, 底泥易被风沙搅动, 水体透明度受到影响数值偏低. 夏、秋季节水华暴发时水体透明度更低, 这主要因为较 低的透明度造成水下光强减弱有利于水华蓝藻的生长 (蓝藻具有较强的低光补偿机制, 即使在较低的光照 强度下也能正常生长), 而蓝藻的大量生长形成的水华又大大降低了水体的透明度. 综上所述, 滇池马村湾 和海东湾理化因子分布、变动与藻类生长繁殖是相辅相成的:由于适宜蓝藻生长的氮、磷、温度、光照、 $\mathrm{pH}$ 等 各理化因子的影响,使该水域极易形成具有较高的微囊藻种群优势度的蓝藻水华,而水华的形成不仅直接 或间接地影响了各项理化指标变化,同时也影响了水体中微囊藻毒素的分布与变化.

\section{2 微囊藻毒素与各理化因素相关性分析}

微囊藻毒素的产生主要受磷的控制, Sivonen 研究了颤藻的产毒条件 ${ }^{[14]}$, 发现磷在 $0.1-0.4 \mathrm{mg} / \mathrm{L}$ 范围 内微囊藻毒素含量随磷浓度增加而增加, 但更高磷浓度对促进微囊藻毒素产生的效应不明显. 在对马村湾、 海东湾总磷与微囊藻毒素进行相关性分析时, 未见其呈现有统计意义的相关性, 可能是因为两湖湾的总磷 含量较高, 超出了磷对微囊藻毒素产生的刺激效应范围, 这和 Wicks 对南非 Hartbeespoort 水库总磷与微囊 造毒素进行相关分析时未发现两者之间具有相关关系的报道是一致的 ${ }^{[15]}$. 本次研究发现马村湾、海东湾微 囊藻毒素含量与总氮含量呈现非常显著的负相关, 这与以往的研究中所发现的总氮含量与微囊藻毒素含量 呈现正相关的报道 ${ }^{[14,16,17]}$ 似乎是矛盾的. 这需要联系影响两湾的环境因素来考虑, 由于降雨将大量的氮、 磷通过 7 条河道带人水体, 造成两湾总氮含量水平的上升, 而本研究表明马村湾、海东湾微囊藻毒素含量与 光照强度呈正相关, 所以降雨的同时由于光照强度的减弱降低了微囊藻毒素的含量, 故两湾微囊藻毒素同 总氮之间呈现显著的负相关. 从表 2 中可以看出微囊藻毒素与两湾溶解氧含量也呈现较显著的负相关性, 这是由于微囊藻毒素作为一种内毒素, 只有当藻细胞死亡、破裂时才会释放到水体中 ${ }^{[18]}$. 而微囊藻大量死 亡的过程中会消耗水体中的溶解氧, 造成溶解氧含量偏低, 因此当水体由于藻细胞死亡而使毒素含量增加 的同时其溶解氧反而降低, 这一结果表明马村湾、海东湾微囊藻释放毒素的过程与水体溶解氧降低的过程 是同步的. 从表 3 还可以看出马村湾、海东湾微囊藻毒素含量与透明度之间呈现较显著的正相关, 这说明影 响马村湾、海东湾透明度的主要因素是藻类的大量繁殖: 由于活的藻体具有伪空胞能漂浮在水体表面, 造成 透明度的下降,而死亡的藻体则因为伪空胞的破裂沉人水底使得水体透明度上升, 同时释放毒素. 此外, 由 于马村湾、海东湾藻类组成中微囊藻为绝对的优势种, 当微囊藻大量死亡使水体中微囊藻毒素含量增加的 同时, 其在两湾的种群优势度会有所降低. 这使得马村湾、海东湾微囊藻毒素含量与微囊藻种群优势度呈现 较显著的负相关, 也说明了两个湖湾中产生微囊藻毒素的主要种类为微囊藻.

\section{3 影响马村湾、海东湾微囊藻毒素含量的主要因素}

通过对马村湾、海东湾微囊藻毒素含量与各理化因子进行回归分析表明, 影响微囊藻毒素含量的主要 因素是透明度和溶解氧. 此外, 总磷、总氮、叶绿素也是影响两湾毒素含量的主要因素 $\left(R^{2}=0.560, P<\right.$ 0.017 ). 由于马村湾、海东湾特殊的地形使得微囊藻的分布易受风浪的影响, 在湖流场的作用下聚集在个别 样点, 造成各样点微囊藻毒素含量差别较大. 因此, 各因素标准化后形成的回归模型在微囊藻毒素含量较低 时其预测值接近实测值，但当微囊藻毒素含量较高时通过各种各种理化因子预测的毒素含量同实际测定值 之间往往相差较大. 此外, 由于运用逐步回归所建立的模型只以线性回归预测了各回归变量 (转化后的) 与 
微囊藻毒素含量之间量的关系, 当回归变量与微囊藻毒素之间不是线性关系时这种预测的准确度就会下 降. 所以在用以上变量对马村湾、海东湾微囊藻毒素含量进行预测时尚存在一定的局限性,要对其进行准确 的预测有待于进一步研究和采用其他更合适的回归模型.

致谢: 云南省环境监测站参加了本研究的部分工作,在此谨表谢意!

\section{4 参考文献}

[1] Hallegraeff G M. A review of harmful algal bloom and their apparent global increase. Phycologia, 1993, 32 (2) : $79-99$.

[2] Figueiredo D R, Azeiteiro U M, Esteves S M, et al. Microcystin-producing blooms-a serious global public health issue. Ecotoxicology and Environmental Safety, 2004, 59(2) : $151-163$.

[3] Hee-Mock Oh, Seog June Lee, Min-Ho Jang, et al. Microcystin production by microcystis aeruginosa in a phosphorus-limited chemostat. Applied and Environmental Microbiology, 2000, 66:176 - 179.

[4] Watanabe MF, K Harada, K Matsuura, et al. Heptapeptide toxin production during the batch culture of two Microcystis species (cyanobacteria). Journal of Applied Phycology, 1989, 1:161 - 165.

[5] Lawton L A, C Edwards, G A Codd. Extraction and high-performance liquid chromatographic method for the determination of microcystins in raw and treated waters. Analyst, 1994, 119:1525-1530.

[6] 章宗涉, 黄详飞主编. 淡水浮游生物研究方法. 北京: 科学出版社, 1991:345-347.

[7] 魏复盛主编. 水和废水监测分析方法 (第三版). 北京: 中国环境科学出版社, 1998:278-285, 359361.

[8] WHO. The Guidelines for Drinking-water Quality, Voluma-Health criteria and other supporting information. Geneva,1998:95 - 110.

[9] 夏学惠, 东野脉兴, 周建民等. 滇池现代沉积物中磷的地球化学及其对环境影响. 沉积学报, 2002, 22 ( 3 ) : 416-420.

[10] 李 益, 彭永岸, 王玉朝等. 滇池污染特征及治理对策. 云南地理环境研究, 2003, 15(4):32-38.

[11] 黄富荣. 云南滇池地区下寒武统磷块岩的稀土元素特征及其地球化学演化. 稀土, 1995, 16(4):48 -51 .

[12] 刘永定, 范 晓, 胡征宇主编. 中国藻类学研究. 武汉:武汉出版社, 2001: 245 .

[13] 聂国朝. 襄阳护城河水体中溶解氧含量研究. 水土保持研究, 2004, 11(1)：60-62, 112.

[14] Sivonen K. Effects of light, temperature, nitrate, orthophosphate and bacteria on growth of and hepatatoxin production by Oscillatoria agardhii strains. Applied and Environ Microbiol,1990, 56:2658 - 2666.

[15] Wicks R J, Thiel P G. Environmental factors affecting the production of peptide toxin floating scums of the cyanobacterium Microcystis aeruginosa in a hypertrophic african reservoir. Environmental Science and Technology, 1990, $24: 1413-1418$.

[16] 张志红, 赵金明, 蒋颂辉等. 淀山湖夏秋季微囊藻毒素 - LR 和类毒素 - A 分布状况及其影响因素. 卫生研究, 2003, 32(4): 316-319.

[17] 连 民, 陈传炜, 俞顺章等. 淀山湖夏季微囊藻毒素分布状况及其影响因素. 中国环境科学, 2002, 20 (4) $: 323-327$.

[18] Carmichael W W. The toxins of cyanobacteria. Scientific American, 1994, 270(1):64 - 70 . 